\title{
Parâmetros quantitativos de hastes florais de gladíolo conforme a data de plantio em ambiente subtropical
}

\author{
Natalia Teixeira Schwab(1), Nereu Augusto Streck(1), Bruna San Martin Rolim Ribeiro(1), Camila Coelho Becker ${ }^{(1)}$, \\ Josana Andreia Langner ${ }^{(1)}$, Lilian Osmari Uhlmann ${ }^{(1)}$ e Giovana Ghisleni Ribas ${ }^{(1)}$ \\ (1)Universidade Federal de Santa Maria. Avenida Roraima, no 1.000, Cidade Universitária, Prédio 77, Sala 2, Bairro Camobi, \\ CEP 97105-900 Santa Maria, RS, Brasil. E-mail: natalia_schwab@hotmail.com, nstreck2@yahoo.com.br, brunasanmartin@hotmail.com, \\ camilabecker07@hotmail.com, langnerja@gmail.com, liliuhlmann@yahoo.com.br, giovana.ghisleni@hotmail.com
}

Resumo - O objetivo deste trabalho foi determinar as épocas de cultivo, em ambiente subtropical, em que é possível produzir hastes de gladíolo (Gladiolus x grandiflorus) que atendam aos padrões comerciais quantitativos do mercado nacional de flores de corte. Dois experimentos de campo foram realizados, um de agosto de 2011 a julho de 2012 e outro de agosto de 2012 a julho de 2013, com três cultivares do gladíolo e 12 datas de plantio para cada experimento. O comprimento total da haste, o comprimento do pendão e o diâmetro da haste foram avaliados quando as hastes estavam em ponto de colheita, ou seja, quando a cor das pétalas apareceu nos três primeiros floretes na base da haste. Os melhores meses para a produção de hastes de gladíolo são julho, agosto, setembro, fevereiro, março e abril, embora em nenhuma das datas de plantio tenham sido produzidas hastes com parâmetros quantitativos abaixo do padrão mínimo (exceto em períodos com geada, durante o espigamento).

Termos de indexação: Gladiolus x grandiflorus, época de cultivo, floricultura, padrão comercial, qualidade.

\section{Quantitative parameters of gladiolus stems according to planting dates in a subtropical environment}

\begin{abstract}
The objective of this work was to determine the growing seasons, in a subtropical environment, when it is possible to produce gladiolus (Gladiolus $\mathrm{x}$ grandiflorus) stems that meet commercial, quantitative standards for cut flowers of the national market. Two field experiments were carried out - one from August 2011 to July 2012, and the other from August 2012 to July 2013 - with three gladiolus cultivars and 12 planting dates for each experiment. Stem total length, rachis length, and stem diameter were evaluated at the harvesting point, when the petal color appears in the first three florets at the stem base. The best months for production of gladiolus stems are July, August, September, February, March, and April, although in the other planting dates the stem quality was never below the minimum standard (except for the periods of frost during heading).
\end{abstract}

Index terms: Gladiolus x grandiflorus, growing season, floriculture, commercial standard, quality.

\section{Introdução}

O gladíolo (Gladiolus $x$ grandiflorus hort.) é uma importante flor de corte, no mercado da floricultura brasileira, que está frequentemente entre as dez plantas mais comercializadas no Veiling Holambra (Números..., 2013). As hastes florais (espigas) são compostas por floretes de cores variadas, conforme a cultivar, e têm durabilidade pós-colheita de até 15 dias. As cultivares de gladíolo atualmente utilizadas são híbridos obtidos por cruzamentos entre onze espécies (Tombolato et al., 2005), que têm centro de origem na Região Mediterrânea e no Sul da África, onde existem centenas de espécies de gladíolos silvestres (Grevig, 1987; Tombolato et al., 2005; Riaz et al.,
2010). No Brasil, a maior comercialização para hastes de gladíolos ocorre no dia de Finados, mas é uma flor também utilizada para ornamentação de cerimônias e decorações em geral (Schwab et al., 2014).

As flores de corte, inclusive o gladíolo, devem atender a critérios de qualidade sem os quais as hastes são desclassificadas para a comercialização no Veiling Holambra. Entre os critérios, há parâmetros qualitativos e quantitativos da haste floral (Critérios..., 2013). Os qualitativos referem-se às características visuais não mensuráveis, como tortuosidade das hastes, defeitos graves (aqueles que depreciam a aparência e a qualidade do produto e podem aumentar de intensidade com o tempo - como danos causados por mofo de Botrytis, ferrugem, trips e lagartas) e defeitos leves 
(aqueles que depreciam a qualidade, mas não evoluem com o tempo - como queimaduras por sol, danos mecânicos e sintoma de deficiência nutricional).

Os parâmetros quantitativos para gladíolo (Critérios..., 2013) são aqueles que podem ser medidos, como: o comprimento total da haste, que deve variar de 0,75 a $1,10 \mathrm{~m}$, pois hastes menores ou maiores que estes padrões são classificadas em nível inferior; o comprimento do pendão floral (porção onde estão distribuídos os floretes, excluindo-se o pedúnculo), que deve ser no mínimo $40 \%$ do comprimento total da haste (inclui a porção do pendão mais o pedúnculo); e o diâmetro da haste, que deve ser no mínimo de $0,5 \mathrm{~cm}$ para hastes com $0,75 \mathrm{~m}$ de comprimento (as de $0,90 \mathrm{~m}$ de comprimento devem apresentar diâmetro mínimo de $0,8 \mathrm{~cm}$, e aquelas com $1,10 \mathrm{~m}$ de comprimento devem apresentar diâmetro mínimo de 1,0 cm).

Estudos clássicos em ambiente controlado mostraram a influência de fatores ambientais sobre o desenvolvimento e a produção de hastes de gladíolo, tais como intensidade luminosa, comprimento do dia, temperatura, umidade, além da interação entre eles (Shillo \& Havely, 1976a; Shillo \& Havely, 1976b; Shillo \& Havely, 1976c; Shillo \& Havely, 1976d). Nesse contexto, a época de plantio desempenha importante papel no crescimento e na qualidade das hastes florais de gladíolo (Zubair et al., 2006; Ahmad et al., 2011; Akpinar \& Bulut, 2011). Segundo Barbosa (2011), no Brasil, o gladíolo pode ser cultivado em todas as épocas do ano, porém, em alguns períodos, podem ocorrer problemas de cultivo, principalmente em épocas de baixa radiação solar e temperatura, que causam, segundo Severino (2007), atrasos da colheita, plantas com tamanho reduzido, hastes com baixo número de floretes e diminuição da qualidade das plantas. Estes efeitos são esperados de forma mais pronunciada em regiões extratropicais, onde a variação da radiação solar e da temperatura são acentuadas ao longo do ano, porém, não foram encontrados na literatura trabalhos para identificar a melhor data de plantio, para a obtenção de hastes forais de gladíolo com padrão comercial, em regiões subtropicais do Brasil.

O objetivo deste trabalho foi determinar as épocas de cultivo em que é possível produzir hastes de gladíolo, em ambiente subtropical, que atendam aos padrões comerciais quantitativos do mercado nacional de flores de corte.

\section{Material e Métodos}

Dois experimentos de campo foram realizados com a cultura do gladíolo, em Santa Maria, RS (29\%43'23"S e $53^{\circ} 43^{\prime} 15^{\prime \prime} \mathrm{W}$, à altitude de $95 \mathrm{~m}$ ). O experimento 1 foi realizado de agosto de 2011 a julho de 2012, e o experimento 2, de agosto de 2012 a julho de 2013. Santa Maria está localizada na região fisiográfica da Depressão Central do Rio Grande do Sul e apresenta clima Cfa subtropical úmido, com verões quentes e sem estação seca definida -, segundo a classificação de Köppen.

O delineamento experimental em blocos ao acaso foi utilizado em arranjo bifatorial, com quatro repetições, e cada repetição representou uma parcela de 10 plantas. $\mathrm{O}$ fator $\mathrm{A}$ foi composto de três cultivares de gladíolo (Peter Pears, Rose Friendship e Jester, no experimento 1, e Amsterdã, Rose Friendship e Jester, no experimento 2). As cultivares selecionadas apresentaram diferentes durações do ciclo de desenvolvimento (precoce, médio e tardio, respectivamente) e são usadas comercialmente por produtores locais. O fator $\mathrm{B}$ foi composto de 12 datas de plantio mensais, em cada experimento. No experimento 1, as datas de plantio foram: para $2011,05 / 08,02 / 09,03 / 10,01 / 11,01 / 12$; e para 2012 , 04/01/, 01/02, 07/03, 02/04, 02/05, 01/06 e 02/07. No experimento 2, as datas de plantio foram: para 2012, 02/08, 03/09, 04/10,01/11,03/12; e, para 2013, 04/01, 01/02, 01/03, 01/04, 01/05, 03/06 e 02/07.

Em cada data de plantio, foram utilizados cormos comerciais de gladíolo vernalizados, com tamanho entre 14 e $16 \mathrm{~cm}$ de circunferência, que foram plantados em canteiros de 1,00 $\mathrm{m}$ de largura, 17,00 $\mathrm{m}$ de comprimento e $0,10 \mathrm{~m}$ de altura, com duas linhas pareadas, espaçadas de $0,40 \mathrm{~m}$ e $0,20 \mathrm{~m}$ entre plantas, na linha. Apenas uma brotação foi mantida por cormo plantado. Cada época de plantio foi representada por um canteiro, onde estavam distribuídos os blocos, distanciados $1,00 \mathrm{~m}$ entre si. A adubação foi realizada de acordo com a análise de fertilidade do solo, com uma aplicação de base de $500 \mathrm{~kg} \mathrm{ha}^{-1}$ da fórmula de $\mathrm{N}-\mathrm{P}_{2} \mathrm{O}_{5}-\mathrm{K}_{2} \mathrm{O}$ 05-20-20, a $0,15 \mathrm{~m}$ de profundidade, e uma aplicação de cobertura com $350 \mathrm{~kg} \mathrm{ha}^{-1}$ de ureia $(45 \% \mathrm{~N})$ quando as plantas apresentavam três folhas. A irrigação foi feita por um sistema de gotejamento, conforme a demanda hídrica da cultura, de modo que as plantas não tiveram deficit hídrico no solo. O tutoramento das plantas foi realizado por meio de três fios de ráfia, amarrados a estacas de bambu fixadas nas extremidades dos canteiros.

Pesq. agropec. bras., Brasília, v.50, n.10, p.902-911, out. 2015 DOI: 10.1590/S0100-204X2015001000006 
Quando as hastes florais estavam em ponto de colheita (três primeiros floretes na base da haste mostrando a cor das pétalas), foram avaliadas seis plantas centrais por repetição - no total de 24 plantas por tratamento. Avaliaram-se, conforme Critérios... (2013), as variáveis comprimento da haste, comprimento do pendão floral (distância desde a inserção do primeiro florete até a ponta da espiga) e diâmetro da haste. $\mathrm{O}$ comprimento da haste foi determinado pela distância da base da planta no solo até a ponta da espiga -, e enquadrado nas classes seguintes: classe 75 , haste com comprimento de $75 \mathrm{~cm}$; classe 90, haste com comprimento de $90 \mathrm{~cm}$; classe 110, haste com comprimento de $110 \mathrm{~cm}$. Hastes com comprimento inferior a $75 \mathrm{~cm}$ não se enquadram no padrão Veiling Holambra. O diâmetro da haste do gladíolo (abaixo da inserção do primeiro florete), para se enquadrar nos padrões do Veiling Holambra, deverá apresentar espessura de acordo com o comprimento, conforme a seguir: classe 75, espessura mínima de $0,5 \mathrm{~cm}$; classe 90, espessura mínima de $0,8 \mathrm{~cm}$; e classe 110 , espessura mínima de $1,0 \mathrm{~cm}$.

A densidade de fluxo de radiação solar global incidente, a temperatura mínima do ar e a temperatura máxima do ar foram medidas diariamente, na estação meteorológica automática do Instituto Nacional de Meteorologia (Inmet), localizada a aproximadamente $150 \mathrm{~m}$ da área experimental.

A análise estatística consistiu de análise de variância e teste de médias pelo teste de Tukey, a 5\% de probabilidade de erro tipo I, para ambos os experimentos. $\mathrm{Na}$ análise de variância, testou-se a interação entre datas de plantio e cultivares (Peter Pears, Rose Friendship e Jester, no experimento 1, e Amsterdã, Rose Friendship e Jester, no experimento 2).

Para identificar fatores que possam explicar as diferenças entre épocas de plantio, quanto aos parâmetros quantitativos de hastes florais de gladíolo, relacionaramse estes parâmetros à temperatura média do ar e à radiação solar acumulada do período da emergência até o ponto de colheita, por meio de análise de regressão simples. Para esta análise, as variáveis comprimento total da haste, comprimento do pendão e diâmetro da haste foram normalizadas dentro de cada cultivar, em cada experimento.

\section{Resultados e Discussão}

Ao longo dos dois anos em que se conduziram os experimentos (plantios de agosto/2011 a julho/2012, para o experimento 1, e agosto/2012 a julho/2013, para o experimento 2), as plantas de gladíolo foram submetidas a diferentes condições meteorológicas (Figura 1), inclusive um evento de forte geada durante o experimento 1 (dias 7, 8 e 9 junho de 2012), com temperatura mínima absoluta de $-2^{\circ} \mathrm{C}$. A temperatura mínima absoluta, durante o experimento 2 , foi $-0,8^{\circ} \mathrm{C}$, enquanto a temperatura máxima absoluta foi $39^{\circ} \mathrm{C}$ e $39,2^{\circ} \mathrm{C}$ para os experimentos 1 e 2 , respectivamente. Vários trabalhos, ainda na década de 1970, mostraram que variações nas condições ambientais, o que inclui a temperatura, podem influenciar o desenvolvimento e a produção de hastes florais de gladíolo (Shillo \& Havely, 1976a; Shillo \& Havely, 1976b; Shillo \& Havely, 1976c; Shillo \& Havely, 1976d). Barbosa (2011) reporta, ainda, que o gladíolo pode ser cultivado ao longo de todas as épocas do ano, porém, em alguns períodos, poderão ocorrer problemas de cultivo, principalmente se houver redução de luminosidade e temperatura, condições típicas do período invernal de regiões subtropicais.

Apenas para o experimento 1 , houve interação significativa entre datas de plantio e cultivares, quanto às variáveis comprimento da haste $(\mathrm{CV}=10,55 \% \mathrm{e}$ $\left.\mathrm{R}^{2}=0,503\right)$, comprimento do pendão ( $\mathrm{CV}=15,75 \%$ e $\left.\mathrm{R}^{2}=0,522\right)$ e diâmetro da haste $(\mathrm{CV}=11,18 \%$ e $\mathrm{R}^{2}=0,479$ ) (Tabela 1). No experimento 2, somente a variável diâmetro da haste $\left(\mathrm{CV}=10,53 \%\right.$ e $\left.\mathrm{R}^{2}=0,404\right)$ apresentou interação significativa entre datas de plantio e cultivares (Tabela 2). Em razão deste resultado, a análise foi desdobrada entre os fatores datas de plantio e cultivares, para as variáveis em que a interação foi significativa (Tabelas 1 e 2). A análise não foi desdobrada (Tabela 3) para as variáveis em que a interação não foi significativa - comprimento da haste e comprimento do pendão, no experimento 2 -, as quais são discutidas a seguir.

Para o comprimento total da haste, nas diferentes datas de plantio do experimento 1 (Tabela 1), os maiores valores foram 123,8, 126,5 e 129,6 cm, para as cultivares Peter Pears, Jester e Rose Friendship, respectivamente, plantadas em 02/09/2011, que não diferiu dos plantios em 05/08/2011, 03/10/2011, 01/11/2011, 01/12/2011 e 01/06/2012, para a cultivar Peter Pears, nem dos plantios em 05/08/2011, 03/10/2011, 01/11/2011, 04/01/2012 e 07/03/2012, para a cultivar Jester, e 07/03/2012 para a cultivar Rose Friendship. Os menores valores de comprimento total 

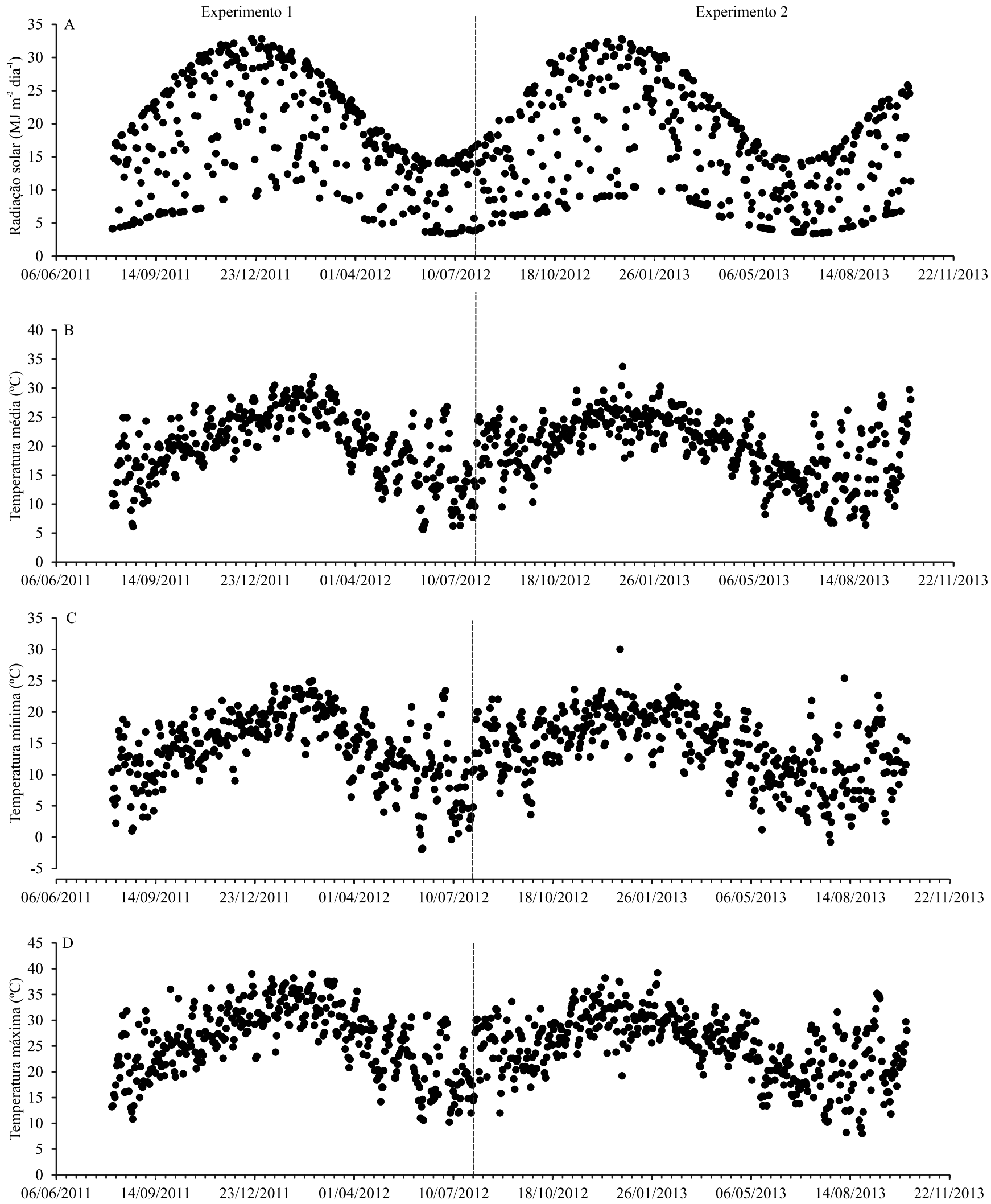

Figura 1. Variação diária: A, densidade do fluxo de radiação solar global; B, temperatura média do ar; C, temperatura mínima do ar; e D, temperatura máxima do ar, de agosto a julho, no experimento 1 (2011/2012) e no experimento 2 (2012/2013). A linha vertical tracejada separa o experimento 1 do experimento 2 . 
da haste (Tabela 1) foram $75,8 \mathrm{~cm}$ para 'Peter Pears' cultivada em 02/07/2011, 90,6 cm para 'Jester' plantada

Tabela 1. Comprimento total da haste, comprimento do pendão e diâmetro da haste, das cultivares Peter Pears, Jester e Rose Friendship, cultivadas em várias datas de plantio durante o experimento 1, em 2011/2012 ${ }^{(1)}$.

\begin{tabular}{|c|c|c|c|}
\hline \multirow{2}{*}{$\begin{array}{l}\text { Data de } \\
\text { plantio }\end{array}$} & \multicolumn{3}{|c|}{ Cultivar } \\
\hline & Peter Pears & Jester & Rose Friendship \\
\hline & \multicolumn{3}{|c|}{ Comprimento total da haste $(\mathrm{cm})$} \\
\hline 05/08/2011 & $112,9 \mathrm{Aab}$ & $109,4 \mathrm{Aabc}$ & - \\
\hline $02 / 09 / 2011$ & $123,8 \mathrm{Aa}$ & $126,5 \mathrm{Aa}$ & $129,6 \mathrm{Aa}$ \\
\hline $03 / 10 / 2011$ & $119,9 \mathrm{Aa}$ & $120,7 \mathrm{Aab}$ & $112,5 \mathrm{Ab}$ \\
\hline $01 / 11 / 2011$ & $110,7 \mathrm{Aab}$ & $110,2 \mathrm{Aabc}$ & $103,4 \mathrm{Abc}$ \\
\hline $01 / 12 / 2011$ & $106,4 \mathrm{Aab}$ & $108,5 \mathrm{Abc}$ & $88,0 \mathrm{Bd}$ \\
\hline $04 / 01 / 2012$ & $100,4 \mathrm{Ab}$ & $109,4 \mathrm{Aabc}$ & $100,9 \mathrm{Abcd}$ \\
\hline $01 / 02 / 2012$ & $96,8 \mathrm{Ab}$ & $104,6 \mathrm{Abcd}$ & - \\
\hline 07/03/2012 & - & $117,5 \mathrm{Aab}$ & $115,0 \mathrm{Aab}$ \\
\hline $02 / 04 / 2012$ & - & - & - \\
\hline 02/05/2012 & - & 94,3 Acd & 95,7Acd \\
\hline 01/06/2012 & $110,3 \mathrm{Aab}$ & $90,6 \mathrm{Bd}$ & $90,9 \mathrm{Bcd}$ \\
\hline $02 / 07 / 2012$ & $75,8 \mathrm{Ac}$ & $91,2 \mathrm{Ad}$ & 91,4Acd \\
\hline \multirow[t]{2}{*}{ CV (\%) } & \multicolumn{3}{|c|}{10,55} \\
\hline & \multicolumn{3}{|c|}{ Comprimento do pendão $(\mathrm{cm})$} \\
\hline 05/08/2011 & $60,1 \mathrm{Aab}$ & 57,7Aab & - \\
\hline 02/09/2011 & $62,9 \mathrm{Aa}$ & $62,4 \mathrm{Aa}$ & $59,8 \mathrm{Aa}$ \\
\hline 03/10/2011 & $57,0 \mathrm{Aabc}$ & $52,9 \mathrm{Aabc}$ & $51,8 \mathrm{Aab}$ \\
\hline $01 / 11 / 2011$ & $48,8 \mathrm{ABbcd}$ & $50,3 \mathrm{Abcd}$ & $44,9 \mathrm{Bbc}$ \\
\hline $01 / 12 / 2011$ & $44,2 \mathrm{ABcde}$ & $49,2 \mathrm{Abcd}$ & $37,9 \mathrm{Bc}$ \\
\hline 04/01/2012 & $35,6 \mathrm{Bde}$ & 44,8 Acd & $38,6 \mathrm{Bc}$ \\
\hline $01 / 02 / 2012$ & $36,2 \mathrm{Bde}$ & 43,6 Acd & - \\
\hline 07/03/2012 & - & $53,8 \mathrm{Aabc}$ & $52,7 \mathrm{Aab}$ \\
\hline $02 / 04 / 2012$ & - & - & - \\
\hline $02 / 05 / 2012$ & - & 44,3Acd & $44,5 \mathrm{Abc}$ \\
\hline 01/06/2012 & 49,2Aabcd & $43,6 \mathrm{ABcd}$ & $37,9 \mathrm{Bc}$ \\
\hline $02 / 07 / 2012$ & $30,9 \mathrm{Ae}$ & 41,4Ad & $38,0 \mathrm{Ac}$ \\
\hline \multirow[t]{2}{*}{ CV $(\%)$} & & 15,75 & \\
\hline & \multicolumn{3}{|c|}{ Diâmetro da haste $(\mathrm{cm})$} \\
\hline 05/08/2011 & 0,99Aab & 0,96Aabcd & - \\
\hline 02/09/2011 & $1,03 \mathrm{Ba}$ & $1,10 \mathrm{Aba}$ & $1,11 \mathrm{Aa}$ \\
\hline 03/10/2011 & $1,04 \mathrm{Aa}$ & $1,10 \mathrm{Aa}$ & $1,08 \mathrm{Aa}$ \\
\hline $01 / 11 / 2011$ & 0,98Aabc & $1,04 \mathrm{Aab}$ & 1,01Aab \\
\hline $01 / 12 / 2011$ & $0,82 \mathrm{Abcd}$ & $0,93 \mathrm{Abcd}$ & $0,82 \mathrm{Ad}$ \\
\hline 04/01/2012 & $0,83 \mathrm{Abcd}$ & $0,87 \mathrm{Ad}$ & $0,85 \mathrm{Acd}$ \\
\hline $01 / 02 / 2012$ & $0,74 \mathrm{Bd}$ & 0,89Acd & - \\
\hline 07/03/2012 & - & 1,03Aabc & 0,99Aabc \\
\hline $02 / 04 / 2012$ & - & - & - \\
\hline $02 / 05 / 2012$ & - & $0,87 \mathrm{Ad}$ & $0,89 \mathrm{Abcd}$ \\
\hline 01/06/2012 & $1,05 \mathrm{Aa}$ & $0,87 \mathrm{Ad}$ & $0,88 \mathrm{Abcd}$ \\
\hline $02 / 07 / 2012$ & 0,80 Acd & $0,86 \mathrm{Ad}$ & 0,79Ad \\
\hline CV (\%) & & 11,18 & \\
\hline
\end{tabular}

em 01/06/2012, e 88,0 cm para 'Peter Pears' plantada em $01 / 12 / 2011$, que não diferiram dos plantios em 01/02/2012, 02/05/2012 e 02/07/2012, para 'Jester', e 04/01/2012, 02/05/2012, 01/06/2012 e 02/07/2012 para 'Rose Friendship'. Entre as cultivares (Tabela 1), o comprimento total da haste diferiu apenas nos plantios de 01/12/2011 (Peter Pears e Jester foram maiores) e 01/06/2012 (Peter Pears foi maior).

Segundo Zubair et al. (2006), o crescimento e o rendimento da cultura do gladíolo, que inclui o comprimento da haste floral, depende da época de plantio. Severino (2007) descreve que o cultivo de gladíolo, em épocas de baixa radiação solar e baixa temperatura (meses de inverno), resulta em plantas com tamanho reduzido (menor comprimento da haste) e com baixo número de botões o que, consequentemente, diminui a qualidade comercial das hastes. Uma haste longa é desejável, pois podese aumentar sua durabilidade pós-colheita, fazendo-se cortes na base, com o objetivo de eliminar os tecidos que não apresentam capacidade de absorção de água e, ainda assim, se consegue manter a haste com tamanho comercializável.

O comprimento do pendão apresentou os maiores valores para o plantio realizado em 02/09/2011 (Tabela 1), tendo alcançado $62,9,62,4$ e $59,8 \mathrm{~cm}$, respectivamente, para 'Peter Pears', 'Jester' e 'Rose Friendship', e ultrapassou o mínimo exigido - de 40\%,

Tabela 2. Diâmetro da haste $(\mathrm{cm})$ das cultivares Amsterdã, Jester e Rose Friendship, cultivadas em várias datas de plantio durante o experimento 2, em 2012/2013 ${ }^{(1)}$.

\begin{tabular}{|c|c|c|c|}
\hline \multirow{2}{*}{$\begin{array}{l}\text { Data de } \\
\text { plantio }\end{array}$} & \multicolumn{3}{|c|}{ Cultivar } \\
\hline & Amsterdã & Jester & Rose Friendship \\
\hline $02 / 08 / 2012$ & $1,12 \mathrm{Aab}$ & 1,05Aabc & $1,04 \mathrm{Aa}$ \\
\hline 03/09/2012 & 0,99Aabcd & 0,99Aabc & 0,97Aabc \\
\hline 04/10/2012 & 1,01Aabcd & $0,90 \mathrm{Abcd}$ & $0,87 \mathrm{Abc}$ \\
\hline $01 / 11 / 2012$ & $0,95 \mathrm{Abcd}$ & $0,70 \mathrm{Ae}$ & $0,83 \mathrm{Abc}$ \\
\hline $03 / 12 / 2012$ & $0,89 \mathrm{Ad}$ & 0,74 Ade & - \\
\hline $04 / 01 / 2013$ & $0,92 \mathrm{Acd}$ & 0,86Acde & $0,82 \mathrm{Ac}$ \\
\hline $01 / 02 / 2013$ & 0,92Acd & 0,94Aabcd & $0,88 \mathrm{Abc}$ \\
\hline 01/03/2013 & 1,10Aabc & 1,06Aab & $1,05 \mathrm{Aa}$ \\
\hline $01 / 04 / 2013$ & 1,05ABabcd & $1,06 \mathrm{Aab}$ & $0,98 \mathrm{Bab}$ \\
\hline $01 / 05 / 2013$ & $0,90 \mathrm{Ad}$ & 0,99Aabc & 0,92Aabc \\
\hline 03/06/2013 & 1,04Aabcd & $1,06 \mathrm{Aab}$ & 0,97Aabc \\
\hline $02 / 07 / 2013$ & $1,16 \mathrm{Aa}$ & $1,12 \mathrm{Aa}$ & $0,96 \mathrm{Babc}$ \\
\hline CV (\%) & & 10,53 & \\
\hline
\end{tabular}


pelo Veiling Holambra -, quanto ao comprimento total da haste, que foi de 50,8\% para 'Peter Pears', 49,3\% para 'Jester', e 46,1\% para 'Rose Friendship'. Proporções acima de $40 \%$ garantem um produto com proporção harmônica entre a porção sem flores e o pendão, o que o torna esteticamente agradável. Os valores de comprimento de pendão, obtidos em 02/09/2011, não diferiram estatisticamente dos obtidos em plantios realizados em 05/08/2011, 03/10/2011 e 01/06/2012 para 'Peter Pears', 05/08/2011, 03/10/2011 e 07/03/2012 para 'Jester' e do plantio realizado em 07/03/2012 para 'Rose Friendship'.

Os menores valores de comprimento de pendão (Tabela 1) foram de 30,9, 41,4 e 38,0 cm, para 'Peter Pears', 'Jester' e 'Rose Friendship', respectivamente, plantadas em 02/07/2012. Apesar de o comprimento do pendão, obtido nesta época de plantio, ser o menor em comparação aos das demais épocas, as três cultivares produziram hastes com comprimento de pendão acima de $40 \%$ quanto ao comprimento total da haste, que foi de $40,7 \%$ para 'Peter Pears', 45,4\% para 'Jester', e 41,6\% para 'Rose Friendship'. $\mathrm{O}$ comprimento do pendão floral em proporção igual

Tabela 3. Efeito de cultivar e de data de plantio sobre o comprimento total da haste e o comprimento do pendão de gladíolo cultivado durante o experimento 2, em 2012/2013 ${ }^{(1)}$.

\begin{tabular}{lcc}
\hline Cultivar & $\begin{array}{c}\text { Comprimento total da } \\
\text { haste }(\mathrm{cm})\end{array}$ & $\begin{array}{c}\text { Comprimento do } \\
\text { pendão }(\mathrm{cm})\end{array}$ \\
\hline Amsterdã & $118,88 \mathrm{a}$ & $51,76 \mathrm{a}$ \\
Jester & $113,26 \mathrm{~b}$ & $52,47 \mathrm{a}$ \\
Rose Friendship & $113,03 \mathrm{~b}$ & $50,65 \mathrm{a}$ \\
\hline CV $(\%)$ & 11,82 & 16,45 \\
\hline Data de plantio & & \\
$02 / 08 / 2012$ & $114,07 \mathrm{abcd}$ & $54,05 \mathrm{ab}$ \\
$03 / 09 / 2012$ & $113,60 \mathrm{bcd}$ & $52,81 \mathrm{abc}$ \\
$04 / 10 / 2012$ & $104,08 \mathrm{def}$ & $46,83 \mathrm{~cd}$ \\
$01 / 11 / 2012$ & $94,96 \mathrm{f}$ & $44,33 \mathrm{~d}$ \\
$03 / 12 / 2012$ & $95,94 \mathrm{f}$ & $43,71 \mathrm{~d}$ \\
$04 / 01 / 2013$ & $109,12 \mathrm{cde}$ & $48,48 \mathrm{abcd}$ \\
$01 / 02 / 2013$ & $117,04 \mathrm{abc}$ & $47,79 \mathrm{bcd}$ \\
$01 / 03 / 2013$ & $122,76 \mathrm{ab}$ & $53,28 \mathrm{abc}$ \\
$01 / 04 / 2013$ & $121,37 \mathrm{ab}$ & $52,06 \mathrm{abc}$ \\
$01 / 05 / 2013$ & $101,34 \mathrm{ef}$ & $47,80 \mathrm{bcd}$ \\
$03 / 06 / 2013$ & $115,42 \mathrm{abc}$ & $54,05 \mathrm{ab}$ \\
$02 / 07 / 2013$ & $125,15 \mathrm{a}$ & $55,10 \mathrm{a}$ \\
\hline $\mathrm{CV}(\%)$ & 11,82 & 16,45 \\
\hline
\end{tabular}

(1)Médias seguidas de letras iguais, para o efeito de cultivar e de data de plantio, não diferem pelo teste de Tukey, a $5 \%$ de probabilidade. ou maior à $40 \%$ do comprimento total da haste é um parâmetro quantitativo exigido pelo mercado brasileiro de gladíolos de corte (Critérios..., 2013). Os menores valores de comprimento de pendão, obtidos em 02/07/2012, não diferiram estatisticamente dos obtidos em plantios realizados em: 01/12/2011, 04/01/2012 e 01/02/2012 para 'Peter Pears'; 01/11/2011, 01/12/2011, 04/01/2012, 01/02/2012, 02/05/2012 e 01/06/2012 para 'Jester'; e 01/11/2011, 01/12/2011, 04/01/2012, 02/05/2012 e 01/06/2012 para 'Rose Friendship'.

Entre as cultivares (Tabela 1), houve diferença significativa quanto ao comprimento do pendão, para os plantios realizados em 01/11/2011, 01/12/2011, 04/01/2012, 01/02/2013 e 01/06/2012 e, em geral, a cultivar Jester apresentou valores maiores para este parâmetro, exceto no plantio realizado em junho de 2012.

Zubair et al. (2006) avaliaram diversos parâmetros quantitativos em hastes de gladíolo cultivadas no Paquistão, entre os quais o comprimento da haste quando o primeiro florete estava aberto e o comprimento da haste quando todos os floretes estavam abertos, e concluíram que, para ambos, a interação entre ano de cultivo, época de plantio e cultivares afeta significativamente tais parâmetros, e que para as condições locais, o plantio no mês de dezembro foi o que resultou em maior comprimento das hastes. O parâmetro comprimento do pendão não foi avaliado no estudo desses autores, pois trata-se de um parâmetro exigido pelo mercado brasileiro.

A resistência da haste é diretamente influenciada pelo diâmetro, ou seja, hastes com diâmetros maiores apresentam maior resistência a danos mecânicos, que podem ocorrer ainda na lavoura (causadas pelo vento) ou durante a colheita, embalagem e transporte das hastes (Albuquerque et al., 2010; Farias et al., 2013). No experimento $1\left(\mathrm{CV}=11,18 \%\right.$ e $\left.\mathrm{R}^{2}=0,479\right)$, os maiores valores de diâmetro da haste ocorreram nos plantio realizados em 02/09/2011 e 03/10/2011, para todas as cultivares, e também no plantio realizado em 01/06/2012 para 'Peter Pears' (Tabela 1). Não houve diferença entre os plantios realizados em 05/08/2011 e 01/11/2011 para 'Peter Pears', 05/08/2011, 01/11/2011 e 07/03/2011 para 'Jester', e 01/11/2011 e 07/03/2012 para 'Rose Friendship'.

Os menores valores de diâmetro da haste foram $0,74 \mathrm{~cm}$ para 'Peter Pears', plantada em 01/02/2012, e $0,86 \mathrm{~cm}$ para 'Jester' e $0,79 \mathrm{~cm}$ para 'Rose Friendship' plantadas em 02/07/2012 (Tabela 1). Embora esses 
valores tenham sido baixos em comparação aos obtidos nas outras épocas de plantio, todos ficaram acima do mínimo de $0,5 \mathrm{~cm}$, exigido pelo Veiling Holambra para o diâmetro de hastes de gladíolo (Critérios..., 2013). Os menores valores de diâmetro da haste, obtidos para 'Peter Pears' cultivada em 01/02/2012, não diferiram dos obtidos em 01/12/2011, 04/01/2012 e 02/07/2012. Para a 'Jester', os menores valores de diâmetro da haste, em 02/07/2012, não diferiram daqueles obtidos em 05/08/2011, 01/12/2011, 04/01/2012, 01/02/2012, 02/05/2012 e 01/06/2012. Para 'Rose Friendship', o diâmetro da haste não diferiu dos obtidos em 01/12/2011, 04/01/2012, 02/05/2012 e 01/06/2012. Houve diferença no diâmetro da haste, entre cultivares plantadas na mesma época, apenas nos plantios realizados em setembro/2011 e fevereiro/2012 (Tabela 1).

No experimento $2\left(\mathrm{CV}=10,53 \%\right.$ e $\left.\mathrm{R}^{2}=0,404\right)$, os maiores valores de diâmetro da haste ocorreram nos plantios realizados em 02/07/2013 para 'Amsterdã' e 'Jester', com 1,16 cm e 1,12 cm, respectivamente, e em 01/03/2013 e 02/08/2012 para 'Rose Friendship', com $1,05 \mathrm{~cm}$ e $1,04 \mathrm{~cm}$, respectivamente (Tabela 2). Para 'Amsterdã', o diâmetro da haste obtido em 02/07/2013 não diferiu dos plantios em agosto, setembro e outubro de 2012 e março, abril e junho de 2013. Para a 'Jester', o diâmetro da haste em 02/07/2013 não diferiu daqueles valores obtidos em plantios realizados em agosto e setembro de 2012 e de fevereiro a junho de 2013. Para a 'Rose Friendship', os resultados obtidos nos plantios realizados em agosto/2012 e março/2013 não diferiram dos obtidos em setembro de 2012 e de abril e julho de 2013.

Os menores valores de diâmetro da haste foram $0,89 \mathrm{~cm}$ para 'Amsterdã', $0,70 \mathrm{~cm}$ para 'Jester' e $0,82 \mathrm{~cm}$ para 'Rose Friendship', cultivadas, respectivamente, em 03/12/2012, 01/11/2012 e 04/01/2013 (Tabela 2). Da mesma forma que para o experimento 1 , nenhum dos valores ficou abaixo do mínimo de $0,5 \mathrm{~cm}$, conforme critérios descritos para gladíolos de corte pelo Veiling Holambra. Para 'Amsterdã', o menor valor obtido em 03/12/2012 não diferiu daqueles em plantios realizados de setembro a novembro de 2012 e em janeiro, fevereiro, abril, maio e junho de 2013. Para 'Jester', o valor de $0,70 \mathrm{~cm}$, obtido em plantio realizado em $01 / 11 / 2012$, não diferiu dos valores de 0,74 e $0,86 \mathrm{~cm}$ nos plantios realizados em 03/12/2012 e 04/01/2013, respectivamente. Para 'Rose Friendship', o menor valor de diâmetro da haste, obtido em 04/01/2013, não diferiu dos valores encontrados em plantios realizados de setembro a novembro de 2012 e em fevereiro, maio, junho e julho de 2013. Houve diferença de diâmetro da haste entre cultivares plantadas em 01/04/2013 (Tabela 2).

Nardi et al. (2001) estudaram a influência da época de plantio e da densidade populacional, sobre o diâmetro de hastes de crisântemo, e obtiveram maior número de hastes com diâmetro superior no cultivo de primavera do que no de outono. Embora o diâmetro da haste confira rigidez à haste e agregue, por consequência, qualidade ao produto final, a maioria das pesquisas em floricultura se detém apenas na avaliação do diâmetro da flor ou inflorescência.

$\mathrm{Na}$ Tabela 3, apresenta-se o efeito das cultivares de gladíolo e da data de plantio sobre o comprimento total das hastes $\left(\mathrm{CV}=11,82 \%\right.$ e $\left.\mathrm{R}^{2}=0,336\right)$ e o comprimento do pendão $\left(\mathrm{CV}=16,45 \%\right.$ e $\left.\mathrm{R}^{2}=0,184\right)$ no experimento 2 . Houve diferença significativa entre as cultivares apenas quanto ao parâmetro comprimento total da haste, em que a 'Amsterdã' apresentou valores superiores aos das demais. Todas as cultivares foram enquadradas na classe 110, segundo normas do Veiling Holambra (Critérios..., 2013).

Quanto ao efeito da data de plantio (Tabela 3), tanto para o comprimento total da haste quanto para o comprimento do pendão, os melhores resultados foram obtidos no plantio de $02 / 07 / 2013$, e quanto ao parâmetro comprimento total da haste, esta data não diferiu das dos plantios nos meses de agosto/2012 e fevereiro, março, abril e junho de 2013. Para o parâmetro comprimento do pendão, o valor obtido em 02/07/2013 não diferiu daqueles encontrados em agosto e setembro de 2012 e janeiro, março, abril e julho de 2013.

$\mathrm{Na}$ Figura 2, se apresenta a classe de comercialização de hastes de gladíolo (classes 110, 90 e 75), segundo o Veiling Holambra (Critérios..., 2013), para as quatro cultivares, nos experimentos 1 e 2 . Em 54,7\% dos casos, as hastes de gladíolo foram classificadas como classe $90,31,3 \%$ como classe 110 , e apenas $14,1 \%$ dos casos como classe 75. A classe 75, com menor valor de comercialização, foi obtida nos plantios realizados nos meses de outubro, novembro, dezembro e julho, para 'Rose Friendship'; janeiro, fevereiro e julho, para 'Peter Pears'; e novembro e dezembro para 'Jester'.

$\mathrm{Na}$ Figura 3, se apresentam: a relação entre temperatura média do ar e a radiação solar acumulada, do período entre a emergência das plantas até o ponto de colheita das hastes e o comprimento total da haste 


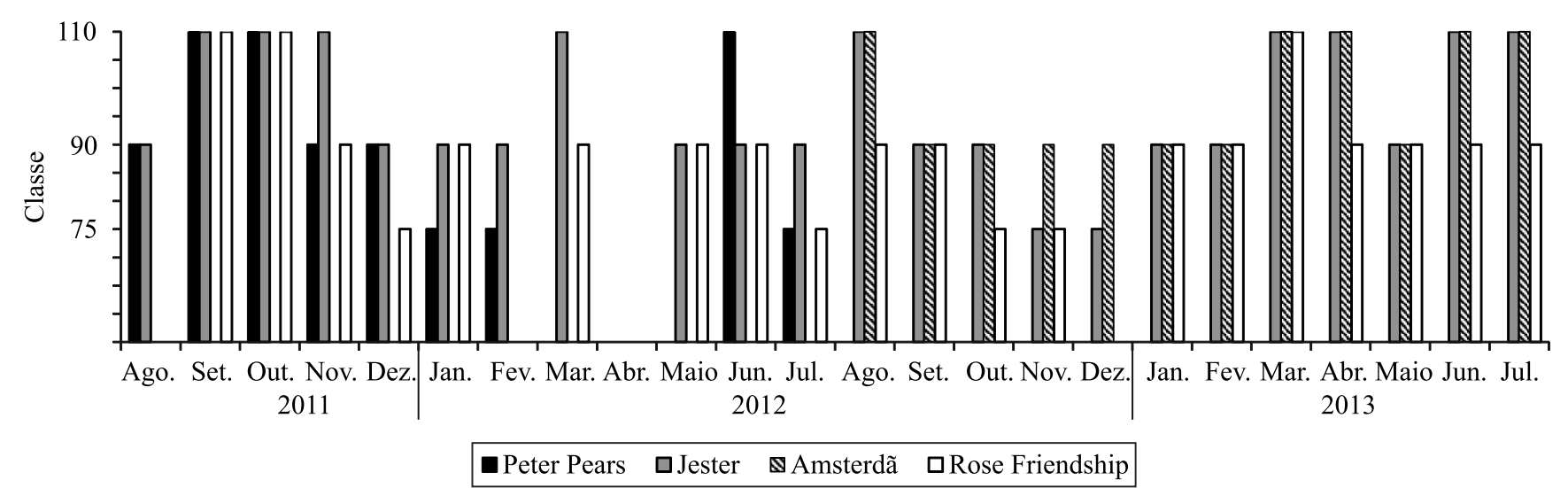

Figura 2. Classes de comercialização de hastes de gladíolo, de acordo com (Critérios..., 2013), para as cultivares Peter Pears, Jester, Rose Friendship e Amsterdã, em diferentes datas de plantio: experimento 1, agosto/2011 a julho/2012; e experimento 2, agosto/2012 a julho/2013.
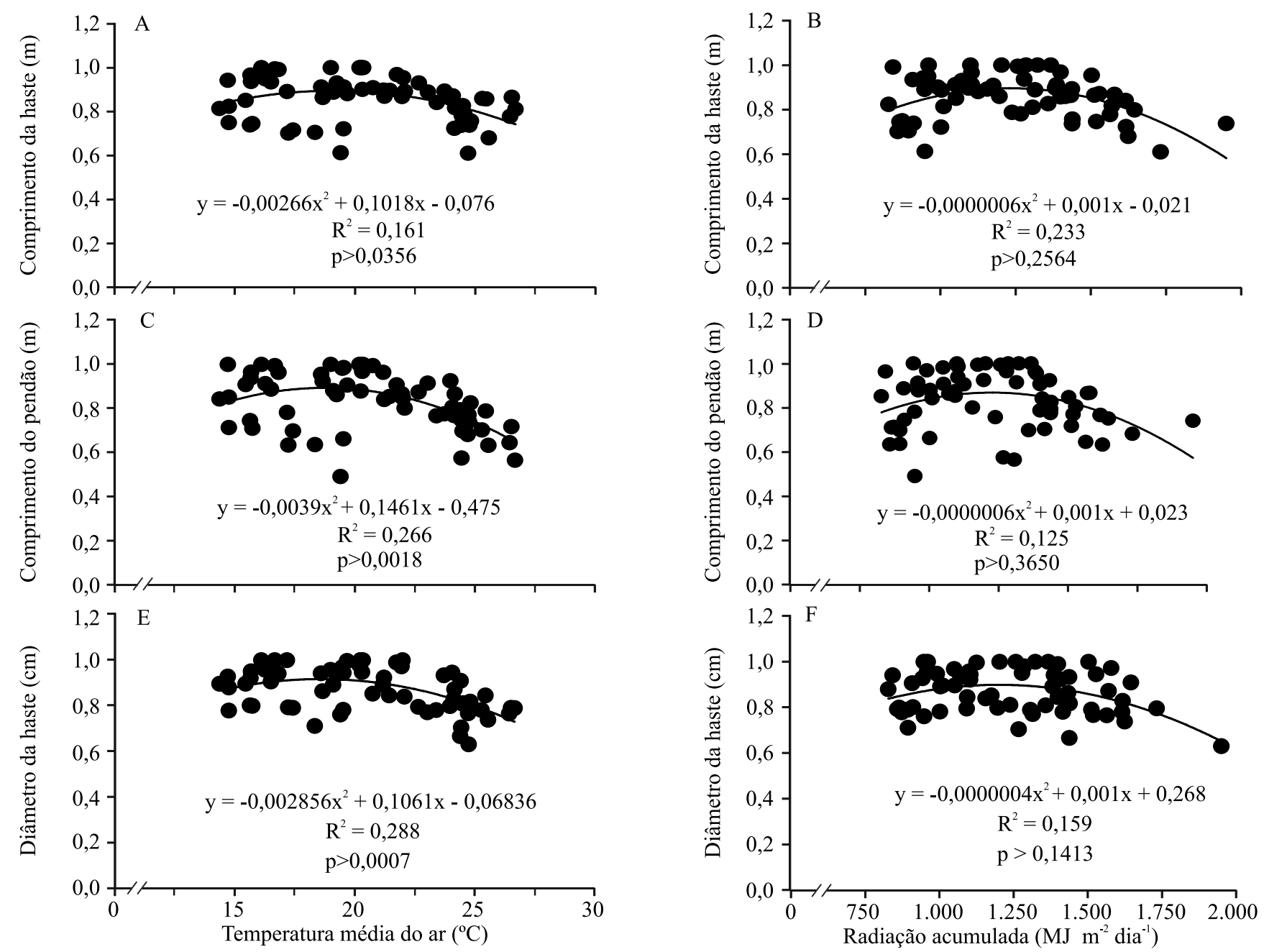

Figura 3. Relação entre comprimento total da haste (A, B), comprimento do pendão $(C, D)$ e diâmetro da haste $(E, F)$ normalizados de gladíolo, e temperatura média do ar e radiação solar acumulada, da emergência da cultura até o ponto de colheita. Dados de quatro cultivares - Peter Pears, Rose Friendship, Jester e Amsterdã - e dois experimentos, com 12 datas de plantio em cada experimento, em Santa Maria, RS. 
(Figura $3 \mathrm{~A}$ e B); o comprimento do pendão (Figura $3 \mathrm{C}$ e D); e o diâmetro da haste (Figura 3 E e F). Houve efeito quadrático significativo da temperatura do ar sobre as variáveis dos parâmetros quantitativos (Figura $3 \mathrm{~A}, \mathrm{C} \mathrm{e}$ E), com ponto de máxima em $19,1,18,7$ e $18,6^{\circ} \mathrm{C}$, que são as temperaturas ótimas para o comprimento total da haste, o comprimento do pendão e o diâmetro da haste, respectivamente, ou seja, abaixo ou acima destas temperaturas há redução nos valores dos parâmetros quantitativos em hastes de gladíolo. Não houve efeito significativo da radiação solar sobre os parâmetros comprimento total da haste, comprimento do pendão e diâmetro da haste (Figura 3 B, D e F, respectivamente), o que indica que não há limitação da disponibilidade de energia solar para o gladíolo, ao longo do ano, na região central do Rio Grande do Sul.

Em geral, os resultados obtidos indicam que os plantios de inverno e início de primavera (julho, agosto e setembro) e em final de verão e início de outono (fevereiro, março e abril) são os mais indicados para a cultura do gladíolo na região de Santa Maria, RS, na Depressão Central do Rio Grande do Sul. Plantios nos demais meses também resultam em hastes florais comercializáveis, porém, notou-se que as altas temperaturas durante os meses de dezembro e janeiro, além de reduzir o tamanho das hastes (Figura $3 \mathrm{~A}, \mathrm{C}$ e E), podem ser prejudiciais, pois causam queimadura de sépalas e murchamento temporário das hastes nas horas mais quentes do dia, o que pode depreciar o produto, já que, após a reidratação, algumas hastes ficam tortas. Além disso, durante o inverno, a ocorrência de geadas durante o espigamento pode acarretar a morte dos tecidos dos floretes, como aconteceu na geada de junho de 2012. Durante o inverno de 2013, não houve dano por geada nas hastes florais, pois as temperaturas não foram tão baixas (Figura 1), o que indica que, em alguns anos, é possível a produção de gladíolo ao longo do ano, na região.

\section{Conclusão}

As épocas de cultivo mais indicadas para produzir hastes de gladíolo (Gladiolus x grandiflorus), para atender aos padrões comerciais quantitativos do mercado nacional de flores de corte, são o inverno e início de primavera (julho, agosto e setembro) e o final do verão e início do outono (fevereiro, março e abril), na região da Depressão Central, no Estado do Rio Grande do Sul.

\section{Agradecimentos}

Ao Conselho Nacional de Desenvolvimento Científico e Tecnológico ( $\mathrm{CNPq})$, à Coordenação de Aperfeiçoamento de Pessoal de Nível Superior (Capes) e à Fundação de Amparo à Pesquisa do Estado do Rio Grande do Sul, pela concessão de bolsas de estudo e de produtividade.

\section{Referências}

AHMAD, I.; KHATTAK, A.M.; ARA, N.; AMIN, N.U. Effect of planting dates on the growth of gladiolus corm in Peshawar. Sarhad Journal of Agriculture, v.27, p.195-199, 2011.

AKPINAR, E.; BULUT, Y. Study on the growth and development of some Gladiolus (Gladiolus L.) varieties planted in different time under the ecological conditions of Erzurum. African Journal of Agricultural Research, v.6, p.3143-3148, 2011.

ALBUQUERQUE, A.W. de; ROCHA, E.S.; COSTA, J.P.V. da; FARIAS, A.P.; BASTOS, A.L. Produção de helicônia Golden Torch influenciada pela adubação mineral e orgânica. Revista Brasileira de Engenharia Agrícola e Ambiental, v.14, p.1052-1058, 2010. DOI: $10.1590 /$ S1415-43662010001000005.

BARBOSA, J.G. Palma-de-Santa-Rita: produção comercial de flores e bulbos. Viçosa: Ed. da UFV, 2011. 113p.

CRITÉRIOS de classificação: gladíolo corte. Santo Antônio de Posse: Veiling Holambra, Departamento de Qualidade e Pós-Colheita, [2013?]. 5p.

FARIAS, A.P. de; ALBUQUERQUE, A.W. de; MOURA FILHO, G.; REIS, L.S. Produtividade de Heliconia psittacorum $\mathrm{x}$ Heliconia pathocircinada cv. Golden Tortch sob diferentes fontes de adubação orgânica. Revista Brasileira de Engenharia Agrícola e Ambiental, v.17, p.713-720, 2013. DOI: 10.1590/ S1415-43662013000700004.

GREVIG, A.J. G87-852 Growing gladiolus. Lincoln: University of Nebraska, 1987. 5p. (Historical Materials from University of Nebraska-Lincoln Extension, 978).

NARDI, C.; BELLÉ, R.A.; SCHMIDT, C.M.; TOLEDO, K. dos A. Qualidade de crisântemo (Dendranthema grandiflora Tzevelev.) cv. Snowdon em diferentes populações e épocas de plantio. Ciência Rural, v.31, p.957-961, 2001. DOI: 10.1590/ S0103-84782001000600006.

NÚMEROS do setor [de flores]: mercado interno: nova fotografia do setor 2013. Holambra: Instituto Brasileiro de Floricultura, [2013]. Disponível em: <http://www.ibraflor.com/ns_mer_interno. php>. Acesso em: 19 jun. 2013.

RIAZ, T.; KHAN, S.N.; JAVAID, A. Management of Fusarium corm rot of gladiolus (Gladiolus grandiflorus sect. Blandus cv. Aarti) by using leaves of allelopathic plants. African Journal of Biotechnology, v.30, p.4681-4686, 2010.

SCHWAB, N.T.; STRECK, N.A.; REHBEIN, A.; RIBEIRO, B.S.M.R.; ULHMANN, L.O.; LANGNER, J.A.; BECKER, C.C. Dimensões lineares da folha e seu uso na determinação do perfil 
vertical foliar de gladíolo. Bragantia, v.73, p.97-105, 2014. DOI: 10.1590/brag.2014.014.

SEVERINO, C.A. de M. Cultivo comercial de Palma de Santa Rita (Gladiolus sp. Tourm.). Brasília: Ibict, Serviço Brasileiro de Respostas Técnicas; Salvador: Rede de Tecnologia da Bahia, 2007. 22p.

SHILLO, R.; HAVELY, A.H. The effect of various environmental factors on flowering of gladiolus. I. Light intensity. Scientia Horticulturae, v.4, p.131-137, 1976a. DOI: 10.1016/ S0304-4238(76)80004-0.

SHILLO, R.; HAVELY, A.H. The effect of various environmental factors on flowering of gladiolus. II. Length of the day. Scientia Horticulturae, v.4, p.139-146, 1976b. DOI: 10.1016/ S0304-4238(76)80005-2.

SHILLO, R.; HAVELY, A.H. The effect of various environmental factors on flowering of gladiolus. III. Temperature and moisture.
Scientia Horticulturae, v.4, p.147-155, 1976c. DOI: 10.1016/ S0304-4238(76)80006-4.

SHILLO, R.; HAVELY, A.H. The effect of various environmental factors on flowering of gladiolus. IV. Interaction of environmental factors - general discussion. Scientia Horticulturae, v.4, p.157-162, 1976d. DOI: 10.1016/S0304-4238(76)80007-6.

TOMBOLATO, A.F.C.; CASTRO, J.L.; MATTHES, L.A.F.; LEME, J.M. Melhoramento genético do gladíolo no IAC: novas cultivares 'IAC Carmim' e 'IAC Paranapanema'. Científica, v.33, p.142-147, 2005.

ZUBAIR, M.; WAZIR, F.K.; AKHTAR, S.; AYUB, G. Planting dates affect floral characteristics of gladiolus under the soil and climatic conditions of Peshawar. Pakistan Journal of Biological Sciences, v.9, p.1669-1676, 2006.

Recebido em 11 de dezembro de 2014 e aprovado em 29 de junho de 2015 